\title{
Effects of familiar versus unfamiliar therapists on responding in the analog functional analysis
}

Carie Lynn English

West Virginia University

Follow this and additional works at: https://researchrepository.wvu.edu/etd

\section{Recommended Citation}

English, Carie Lynn, "Effects of familiar versus unfamiliar therapists on responding in the analog functional analysis" (2002). Graduate Theses, Dissertations, and Problem Reports. 776.

https://researchrepository.wvu.edu/etd/776

This Thesis is protected by copyright and/or related rights. It has been brought to you by the The Research Repository @ WVU with permission from the rights-holder(s). You are free to use this Thesis in any way that is permitted by the copyright and related rights legislation that applies to your use. For other uses you must obtain permission from the rights-holder(s) directly, unless additional rights are indicated by a Creative Commons license in the record and/ or on the work itself. This Thesis has been accepted for inclusion in WVU Graduate Theses, Dissertations, and Problem Reports collection by an authorized administrator of The Research Repository @ WVU. For more information, please contact researchrepository@mail.wvu.edu. 


\title{
Effects of Familiar Versus Unfamiliar Therapists on Responding in the Analog Functional Analysis
}

\author{
Carie L. English \\ Thesis submitted to the College of Arts and Sciences \\ at West Virginia University \\ in partial fulfillment of the requirements \\ for the degree of \\ Master of Arts \\ in \\ Psychology \\ Cynthia M. Anderson, Ph.D., Committee Chair \\ Philip N. Chase, Ph.D. \\ Joseph R. Scotti, Ph.D. \\ Department of Psychology
}

Morgantown, West Virginia

2002

Keywords: Functional analysis, assessment, problem behavior, developmental disabilities 


\section{Abstract \\ Effects of Familiar Versus Unfamiliar Therapists on Responding in the Analog Functional Analysis}

\section{Carie L. English}

The analog functional analysis involves the manipulation of pre-determined antecedent and consequent events and typically is conducted by trained experimenters. Research has evaluated the effects of including a broader range of antecedent variables in the analog. Inclusion of caregivers is one potential antecedent that may alter problem behavior. The purpose of this study was to evaluate the effects of including caregivers in the analog. Four individuals with developmental disabilities and their caregivers served as participants. The differential effects of caregivers and experimenters as therapists were evaluated. For 3 of 4 participants, different patterns of responding were observed when caregivers versus experimenters conducted the functional analysis. Integrity data suggested that skills needed for conducting an analog can be easily acquired. Finally, the effect of participating in the analog on caregiver knowledge of functional relations was examined. All four caregivers demonstrated an increase in knowledge of functional relations following participation in the study. 


\section{Table of Contents}

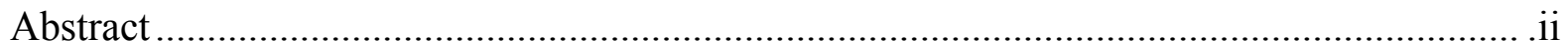

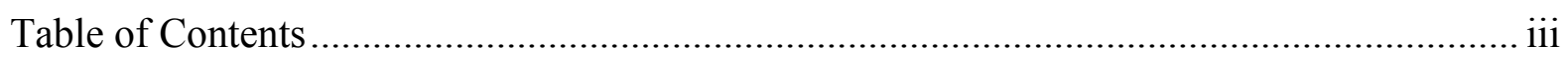

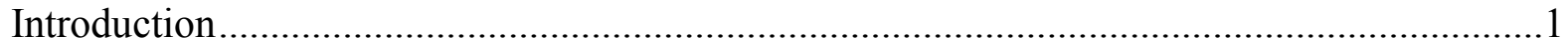

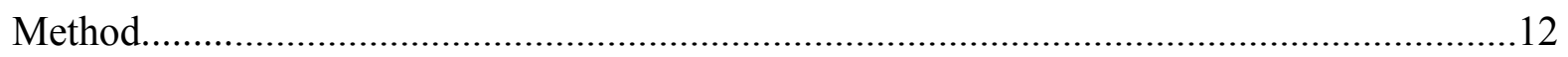

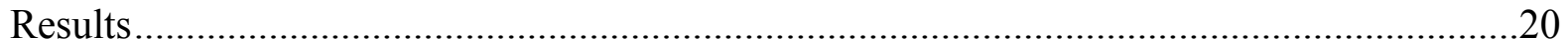

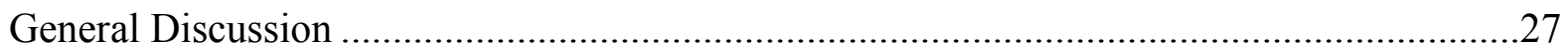

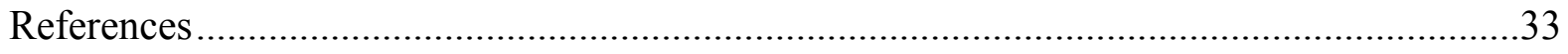

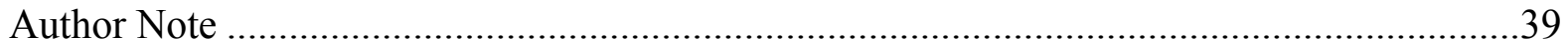

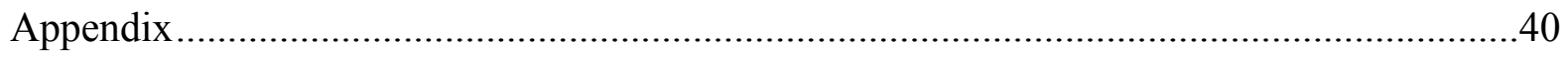

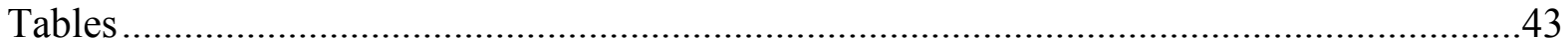

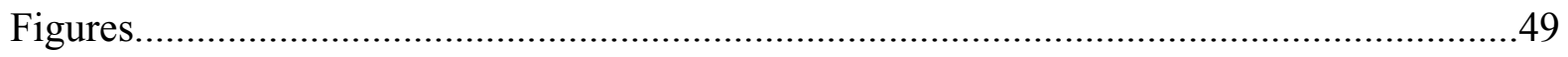

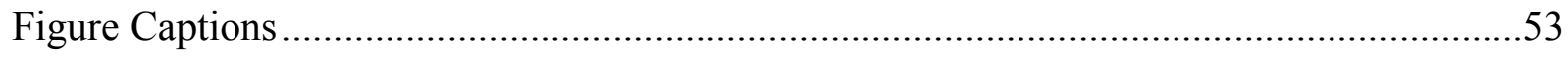




\section{Effects of Familiar Versus Unfamiliar Therapists on Responding in the Analog Functional Analysis}

Over the past several decades, the development and refinement of functional assessment methodology has greatly improved the ability of behavior analysts to develop effective interventions for severe problem behavior. To illustrate, a growing body of research has demonstrated that interventions matched to the function of problem behavior are likely to be more effective than interventions that are arbitrarily implemented (e.g., Iwata, Pace, Cowdery, \& Miltenberger, 1994; Iwata, Pace, Dorsey, et al., 1994; Mace et al., 1988; Repp, Felce, \& Barton, 1988). Additionally, a correlation between the use of pre-treatment functional assessments in the literature and a decrease in the use of interventions involving aversive procedures has been observed (Pelios, Morren, Tesch, \& Axlerod, 1999).

There are numerous functional assessment techniques reported in the literature including, interviews (O’Neill, Horner, Albin, Storey, \& Sprague, 1989), descriptive analyses (Bijou, Peterson, \& Ault, 1968), and the analog functional analysis or derivatives thereof (e.g., brief functional analysis, Northup et al. 1991). Of existing methods, the analog functional analysis (Iwata, Dorsey, Slifer, Bauman, \& Richman, 1982/1994) is used often in empirical studies, and because it yields the greatest degree of experimental control, is generally considered to be the most effective means of reliably demonstrating environment-behavior relations (Lerman \& Iwata, 1993).

The analog functional analysis typically is conducted using a multielement design in which prescribed antecedent and consequent stimuli are systematically varied. The following conditions often are conducted: attention, demand, tangible, play, and alone. The purpose of the attention condition is to determine whether problem behavior is maintained by the delivery of attention 
from others. In this condition, the antecedent condition is attention deprivation, and the consequence is attention delivery. Brief verbal attention is delivered contingent on problem behavior on a fixed-ratio (FR) 1 schedule. The purpose of the demand condition is to determine if problem behavior is maintained by escape from academic demands or other presumably unpleasant events. In the demand condition, the antecedent condition is the presentation of tasks on a fixed-time (FT) schedule. Contingent on problem behavior, a brief (e.g., $20 \mathrm{~s}$ ) escape from tasks is delivered. The tangible condition is conducted to test the hypothesis that problem behavior is maintained by access to tangibles. The antecedent manipulated during the tangible condition is the removal of the tangible item, and the consequence for problem behavior is 20 -s access to the preferred tangible. The purpose of the play condition is to control for the presence of the experimenter, the presence of preferred tangibles, and the absence of demands. During this condition, the experimenter is present and preferred toys are available. Attention is delivered on a FT schedule. There are no programmed consequences for problem behavior in this condition. The alone condition is conducted if sensory reinforcement is hypothesized to be a maintaining variable for problem behavior. During the alone condition, the participant is alone in the session room and no tangible items are provided. There are no programmed consequences for problem behavior.

Using the analog functional analysis, researchers have demonstrated that problem behavior may be maintained by positive reinforcement, including access to attention (e.g., Fisher, O'Connor, Kurtz, DeLeon, \& Gotjen, 2000; Vollmer, Iwata, Zarcone, Smith, \& Mazaleski, 1993) and access to preferred objects or activities (e.g., Lalli, Casey, \& Kates, 1997; Marcus \& Vollmer, 1996). Research also has demonstrated that problem behavior might be maintained by negative reinforcement, specifically escape or avoidance of task requests (e.g., Vollmer, Marcus, 
\& Ringdahl, 1995; Zarcone, Iwata, Smith, Mazaleski, \& Lerman, 1994). Finally, studies have suggested that problem behavior also might be maintained by sensory reinforcement (e.g., Iwata, Pace, Dorsey, et al., 1994; Piazza, Adelinis, Hanley, Goh, \& Delia, 2000).

Validity of the Analog Functional Analysis

The analog functional analysis manipulates specified environmental stimuli presumed to be similar to the environmental events that individuals contact in their natural environment. Thus, it is assumed that functional relations demonstrated in the analog functional analysis are occurring in the individual's natural environment. That is, the analog functional analysis is assumed to have external validity (Iwata, Vollmer, \& Zarcone, 1990; Iwata, Vollmer, Zarcone, \& Rodgers, 1993; Lerman \& Iwata, 1993). Many researchers have argued that the external validity of the analog has been established through the numerous studies demonstrating effective treatments following an analog functional analysis (e.g., Iwata, Pace, Dorsey, et al., 1994; Lerman \& Iwata, 1993). However, simply demonstrating intervention efficacy following a functional analysis says nothing about the validity of the analog. First, treatment often is implemented in the same environment in which the analysis was conducted in (e.g., clinic room), not in the individual's home, school, or work setting (e.g., Fisher et al., 2000; Hagopian, Fisher, Sullivan, Acquisto, \& LeBlanc, 1998; Shirley, Iwata, Kahng, Mazaleski, \& Lerman, 1997). Second, if the intervention involves an aversive consequence, response suppression may occur even if the aversive stimulus is not related to the function of the problem behavior. For example, contingent electric shock has been shown to suppress self-injurious behavior (SIB) regardless of the function of the behavior (e.g., Griffin, Locke, \& Landers, 1975). Finally, even if the intervention is matched to the variable demonstrated to maintain responding in the analog functional analysis, it has not been shown that all important variables necessarily have been identified (Anderson, Freeman, \& 
Scotti, 1999). An intervention involving additional or different variables may have been more effective.

Recently, a growing number of researchers have voiced concerns about the external validity of the analog functional analysis (e.g., Carr, Yarbrough, \& Langdon, 1997; Halle \& Spradlin, 1993; Iwata et al., 1990; Mace, Lalli, Pinter Lalli, \& Shea, 1993). Researchers have suggested that, for some participants, the analog functional analysis might not reveal all important environment-behavior relations in effect in the natural environment (e.g., Iwata et al., 1990). Furthermore, the stimuli manipulated in the analog functional analysis might differ from the stimuli functionally related to problem behavior in the natural environment (Carr et al., 1997; Mace et al., 1993). For example, Carr and colleagues conducted analog functional analyses with three individuals with developmental disabilities exhibiting problem behavior. Little to no problem behavior was observed in the analog, and consequently, observations were conducted in the natural environment to identify specific variables that might be related to problem behavior. Idiosyncratic variables identified via unstructured observation (e.g., problem behavior during task presentation only when puzzles were present) were then manipulated within a second analog functional analysis. For all participants, the inclusion of idiosyncratic variables in the analog functional analysis resulted in differentiation across conditions and clear functional relations were demonstrated.

Although undifferentiated patterns of responding in the analog functional analysis could result when problem behavior is maintained by idiosyncratic variables not examined in the analysis, the failure of antecedent variables present during the analysis to function as discriminative stimuli or establishing operations also could account for such patterns. Several studies have examined the effects of antecedent variables on response-consequence relations (see 
Smith \& Iwata, 1997, for a review). Specifically, certain variables may affect responseconsequence relations by functioning either as establishing operations or discriminative stimuli. Michael (1993) defines an establishing operation (EO) as any environmental event, operation, or stimulus condition that affects an organism's behavior by temporarily altering the reinforcing effectiveness of other events and thereby altering the frequency of behaviors associated with those reinforcing events. When deprivation occurs due to limited access to a reinforcer, or satiation occurs due to frequent or continuous access to a reinforcer, the effectiveness of that reinforcer is altered. For example, attention from caregivers may generally function as a reinforcer, but if a parent continuously interacts with a child, attention may cease to reinforce responding in that situation. The presence of a discriminative stimulus $\left(\mathrm{S}^{\mathrm{D}}\right)$ also can alter behavior. An $\mathrm{S}^{\mathrm{D}}$ is any stimulus that signals the availability of reinforcement. That is, a response that occurs in the presence of a stimulus is more likely to be reinforced then when the stimulus is absent. As a result, the presence of the $S^{D}$ occasions the response (Catania, 1998). For example, a teacher might reinforce disruptive behavior by delivering attention to a student. At home and in the community, the frequency of the behavior may be low because the behavior is on extinction - attention delivery typically does not follow exhibition of disruptive behavior. The presence of the teacher may act as an $\mathrm{S}^{\mathrm{D}}$, setting the occasion for disruptive behavior because such behavior is more likely to be reinforced in the presence (but not the absence) of the teacher. If the teacher is not present during the functional analysis, problem behavior may be less likely to occur and/or an important component of the functional relation for the problem behavior may not be identified. 
Evaluating the External Validity of the Analog Functional Analysis

Although numerous researchers have questioned the external validity of the analog functional analysis, relatively few empirical studies have examined the extent to which these concerns are valid. One strategy for conducting such research is to include "naturalistic" variables in the analog functional analysis. For example, researchers could conduct informal observations to identify potential variables to include in the analog functional analysis. If researchers went on to conduct a traditional analog functional analysis, as well as an analog analysis that included those idiosyncratic variables, the extent to which different results were obtained with inclusion of these variables could be examined. This approach was used in the study by Carr and colleagues (1997) discussed earlier. Other researchers have taken this approach by examining task type or duration (Smith, Iwata, Goh, \& Shore, 1995), methods of instruction during a demand situation (McComas, Hoch, Paone, \& El-Roy, 2000), and components of socially-mediated reinforcement (Van Camp, Lerman, Kelley, Roane, Contrucci, $\&$ Vorndran, 2000). These studies demonstrate that different patterns of responding may be observed when idiosyncratic variables are included in the analysis.

An alternative to conducting informal observations to identify variables to include in the analog functional analysis is to include variables that are likely to be present across a variety of situations. The presence of caregivers is one such variable because caregivers are present in multiple task situations, as well as in situations in which varying levels of attention or preferred activities are delivered or removed. Including caregivers in the analysis is one way to account for the effect of differential histories in the presence of different individuals. For example, problem behavior may occur when a child's father is present but not when the mother is present because the father has historically attended to aggression whereas the child's mother most often ignores 
it. The child has learned that engaging in aggressive behavior in the presence of the father results in attention from him, but aggressive behavior in the presence of the mother does not result in attention. Functional relations identified in the presence of the caregiver may increase the external validity of the analog functional analysis because events occurring in the natural environment may be better represented.

\section{Caregivers as Therapists in Functional Assessments}

Based on the hypothesis that response patterns may vary when assessments are conducted with caregivers instead of clinic staff, some investigators have used caregivers as therapists in a functional assessment. Research on the use of caregivers has followed three general patterns. First, some researchers (Cooper, Wacker, Sasso, Reimers, \& Donn, 1990; Cooper et al. 1992; Northup, Wacker, Berg, Kelly, Sasso, \& DeRaad, 1994; O’Reilly, Lancioni, King, Lally, \& Dhomhnaill, 2000) have evaluated the utility of caregivers as therapists using experimental analyses other than the analog functional analysis (e.g., brief functional analyses, manipulations of specific antecedent characteristics such as task novelty, task difficulty). Second, researchers have trained caregivers to conduct analog functional analyses (Asmus et al., 1999; Derby et al., 1997). Finally, two studies (Ringdahl \& Sellers, 2000; Sasso et al., 1992) have compared analog analyses conducted by caregivers to analog functional analyses conducted by trained staff.

Caregivers often are used in non-experimental functional assessments, such as descriptive assessments or direct observation. Because these methods of functional assessment do not involve experimental manipulation of environment-behavior relations, it is difficult to examine the potential value of including caregivers. Several studies (Cooper et al., 1990; Cooper et al., 1992; Northup et al., 1994; O’Reilly et al., 2000) have used caregivers as therapists in experimental analyses other than the analog functional analysis. Unfortunately, the potential 
value of caregiver participation is difficult to determine because none of these studies compared obtained results to results obtained from an experimenter-conducted assessment.

Several of the above-mentioned studies (i.e., Northup et al., 1994, O'Reilly et al., 2000) used the brief functional analysis developed by Northup and colleagues (1991). Although studies have demonstrated the utility of the brief functional analysis (Northup et al., 1991; O'Reilly et al., 2000) for developing hypotheses about problem behavior, other studies suggest that problem behavior often is not emitted during the analyses. For example, Derby and colleagues (1992) reported the results of brief functional analyses conducted with 79 individuals and found that $37 \%$ of participants did not exhibit problem behavior during the analysis. Also, when the brief functional analysis is compared to the analog functional analysis, the analog demonstrates functional relations more convincingly as environmental variables are manipulated multiple times (Kahng \& Iwata, 1999). Taken together, existing research suggests that, of available methods of functional assessment, the analog functional analysis allows for the most functional control and is the most robust. Thus, these findings suggest that experimenters should conduct an analog functional analysis when resources to do so are available. Given the large body of research demonstrating the utility of the analog functional analysis in demonstrating environment-behavior relations, future research evaluating the effects of more idiosyncratic environmental variables should use analog methodology. If effects are reliably demonstrated during the analog functional analysis (under systematic control), research could begin examining the validity of using such variables in less controlled methods of functional assessment. To date, four studies have used analog methodology to evaluate the impact of including caregivers on outcomes of analog functional analyses (Asmus et al., 1999; Derby et al., 1997; Ringdahl \& Sellers, 2000; Sasso et al., 1992). Only two of these studies (Ringdahl \& Sellers, 2000; Sasso et 
al., 1992) have compared the results obtained with caregivers with results obtained with experimenters.

Sasso and colleagues (1992) worked with two children with developmental disabilities (one who functioned in the mild to moderate range of mental retardation and one who functioned in the moderate to severe range of mental retardation) and examined the effects of two variables, use of teachers as therapists and setting of the assessment, on functional analysis outcomes. Three analyses were conducted: an experimenter-conducted analog in a controlled environment, a teacher-conducted analog in a classroom environment, and an A-B-C assessment conducted by the teacher. Teachers were trained via written materials and two practice sessions with an experimenter. Results from the A-B-C assessment suggested the same functions for problem behavior as the experimental analyses; however, rates of responding did vary between the A-B-C assessment and the classroom analysis. For both participants, the analog analyses resulted in similar hypotheses about functional relations; however, because data from the two analyses were graphed in different ways (partial interval coding in the experimenter-conducted analog and frequency in the teacher-conducted analog), a comparison of response rates between the two measures could not be completed. It is possible that responding occurred more frequently in one analysis then the other. Because Sasso and colleagues manipulated two variables simultaneously when comparing the analog analyses (who conducted the analysis and the setting of the analysis), the effect of using teachers as therapists cannot be determined separately from the change in setting. That is, it is not clear if similar results would have been obtained if the teacherconducted analysis had been conducted in a clinic environment (as is most typical of analog analyses). 
Ringdahl and Sellers (2000) conducted a study to evaluate the effects of caregivers as therapists in analog functional analyses with three participants with mental retardation. Two participants functioned in the severe range of mental retardation and one functioned in the mild range. A reversal design (ABA) was used to evaluate the effect of different therapists. The analysis was first conducted by the caregiver, and after completion of the caregiver analysis, the experimenter conducted a functional analysis using the same conditions. Finally, the caregiverconducted analysis was repeated. During sessions conducted by caregivers, a trained experimenter remained in the room and coached the caregiver throughout the session. The experimenter did not interact with the children; thus, the caregiver provided all consequences. For all participants, response patterns varied across conditions and phases as a function of behavioral contingencies and therapists. Although similar patterns of responding (i.e., similar functional relations) were observed for two participants, rates of problem behavior increased when the caregiver conducted the analysis. In fact, for one participant, who functioned in the mild range of mental retardation, problem behavior was rarely exhibited in the experimenterconducted phases. For the third participant, who functioned in the severe range of mental retardation, functional relations varied when experimenters, as opposed to the caregiver, conducted sessions. Specifically, the results of the analysis conducted by the caregiver suggested that problem behavior was maintained by attention in the first phase, but the results of the experimenter-conducted analysis suggested that problem behavior was maintained by access to tangibles. In fact, no problem behavior was observed in the attention condition when experimenters conducted the assessment. Upon returning to the caregiver-conducted phase, rates of problem behavior were highest in the tangible and attention conditions suggesting that problem behavior was multiply maintained or that carryover occurred. 
Taken together, these studies suggest that the effect of caregivers as therapists in a functional analysis deserves further investigation. Several studies (Asmus et al., 1999; Cooper et al., 1990; Cooper et al., 1992; Northup et al., 1994; O’Reilly et al., 2000; Ringdahl \& Sellers, 2000; Sasso et al., 1992) have demonstrated that caregivers can be trained to conduct experimental manipulations of environmental variables; however, research to date has not determined whether experimental analyses have greater external validity when conducted by caregivers rather than by trained experimenters or clinic staff. If using caregivers as therapists in a functional analysis does not increase the external of the analysis, then there is little reason to train and use caregivers as therapists. In fact, it is easier and less time consuming for trained experimenters to conduct the analysis rather than training others to do it.

If it is found that including caregivers as therapists increases the external validity of the experimental analysis, then the methods used to train caregivers to participate in these analyses should be evaluated further. Many of the studies using caregivers as therapists in a functional analysis did not explicitly train the caregivers; instead caregivers were coached (i.e., verbally prompted) throughout the procedure (i.e., Asmus et al., 1999; Cooper et al., 1990; Cooper et al., 1992; Ringdahl \& Sellers, 2000). Other studies (i.e., O’Reilly et al., 2000) did not report how caregivers were trained.

Finally, although some anecdotal evidence suggests that caregivers prefer experimental analyses to other sorts of functional assessment because changes in behavior were more clearly observed (Northup et al., 1994; Sasso et al., 1992), no studies have empirically examined whether learning to conduct a functional analysis affects caregiver's behavior. Perhaps participating in a functional analysis results in greater understanding of environment-behavior relations and thus, greater adherence to intervention recommendations. Empirical research 
examining a caregiver's understanding of behavior and/or the probability that the treatment will be implemented and correctly continued given training in functional analysis methodology is needed.

The purpose of this study was to directly examine the role of caregivers as therapists conducting sessions in the analog functional analysis. This was accomplished by conducting analog functional analyses with four participants and evaluating the extent to which differential patterns of responding were obtained when caregivers conducted sessions versus experimenters. Also, the effect of training caregivers to conduct functional analyses on caregiver knowledge of functional relations was examined by administering a questionnaire prior to and following completion of the assessment. Finally, information about events associated with problem behavior in the natural environment was collected by having caregivers collect scatter plot data (Touchette, MacDonald, \& Langer, 1985) to determine if all important variables were present in the analog functional analysis.

\section{Method}

\section{Participants and Setting}

Four children with developmental delays referred for assessment and treatment of problem behavior and their caregivers participated in the study. Brandon was a 7-year-old boy diagnosed with agensis of the corpus callosum and mild to moderate mental retardation. He exhibited aggression consisting of biting, kicking, pushing, hitting, and throwing items at others; and disruption, consisting of throwing items. Brandon communicated verbally and could follow twostep directions. Donna was a 10-year-old girl diagnosed with autism who functioned in the severe to profound range of mental retardation. She exhibited self-injurious behavior (SIB) consisting of hand biting and hitting her legs and head. Donna had no means of expressive 
communication. She was able to follow some simple one-step directions. Natalie, a 16-year-old girl diagnosed with autism and severe mental retardation, exhibited aggression consisting of hitting, kicking, and throwing items at others; disruption consisting of screaming and disrobing; and SIB consisting of hand biting and head banging. She communicated using gestures and approximately 3-5 words. Natalie could follow simple one-step directions. Shawn, a 5-year-old boy diagnosed with autism and functioning in the mild range of mental retardation, exhibited aggression consisting of hitting, kicking, and throwing items at others and disruption consisting of screaming and throwing things. He communicated verbally and could follow two-step directions.

All sessions were conducted in a therapy room in the Department of Psychology at West Virginia University, which contained a table, chairs, and materials relevant to each condition. Sessions lasted for $10 \mathrm{~min}$ and were conducted for approximately 2-4 hours daily, 3 to 5 times per week.

The caregivers consisted of children's custodial guardians or teachers. For Brandon and Shawn, their biological mothers served as the caregiver in their assessments. Brandon's mother was in her thirty's and had a college education. Shawn's mother was in her thirty's and had a high school education. Donna's legal guardian of seven years, her grandmother, conducted her assessment. Donna's grandmother was in her sixty's and had a high school education. For Natalie, her classroom teacher for four years conducted her assessment. Natalie's teacher was a male in his thirty's with a college education.

\section{Response Definitions and Interobserver Agreement}

Data were collected on problem behavior including aggression, disruption, and SIB. Aggression included: (a) biting, defined as closure of child's upper and lower jaw on any part of 
therapist; (b) hitting, scored when the child's hand or open or closed fist contacted the therapist; (c) kicking, defined as the child's leg or foot contacting the therapist; (d) pinching, defined as closure of child's finger(s) and thumb on the therapist; (e) pushing, defined as forceful contact of child's hands against therapist, resulting in movement of therapist's body away from the direction of the contact; and (f) throwing items, scored when items hit or landed within 1' of therapist. Disruption included: (a) throwing items that landed further then 1' away from therapist; (b) screaming, defined as vocalizations louder then conversational level; and (c) disrobing, defined as lifting up or removing clothing resulting in skin other than arms and feet showing. SIB included: (a) hand biting, defined as closure of the upper and lower jaw on hand or arms; (b) head or body hitting, defined as forceful contact between hand and the head or legs, and (c) head banging, defined as contact between the head and a stationary object. Data were collected as well on therapist (i.e., the person conducting the session—either the caregiver or the experimenter) responses including prompts (verbal, gestural, physical), attention delivery, tangible removal and delivery, and onset and offset of escape. Therapist responses are defined in Table 1.

Observers collected data on response frequency of problem behavior and therapist responding using continuous recording on a real-time data collection program on desktop and hand-held computers (Psion Workabout) during both in vivo and recorded sessions. Data collectors were trained with this type of data collection until agreement scores were $80 \%$ or higher on all target responses for three consecutive sessions prior to collecting data for this study. Two observers independently scored responses across at least 33\% of the sessions for each phase. Agreement coefficients were calculated by dividing sessions into continuous 10 -s intervals, and comparing observers' records for each interval and then dividing the smaller 
number of responses recorded by the larger number of responses recorded. The proportions were then averaged across the session and multiplied by 100 to obtain an agreement coefficient. Mean agreement scores for child and adult responses are listed in Table 2.

\section{Integrity Measurement}

The occurrence of specific stimuli at certain times is critical to a demonstration of functional control in the analog functional analysis, as causal relations can be identified using the analog functional analysis only when pre-specified environmental variables reliably occur at specified times. For example, if responding is high in the attention condition, but low in other conditions, it is assumed that social-positive reinforcement maintains problem behavior. This assumption can be made because it is known that, in the attention condition, attention deprivation preceded problem behavior, and attention delivery followed problem behavior. In addition, demands were not present and the presence of tangible items was controlled. Some researchers (Paisey, Whitney, \& Hislop, 1990) have suggested that caregivers cannot be trained to accurately conduct an analog functional analysis and it therefore seemed important to evaluate the extent to which caregivers delivered appropriate antecedent and consequent stimuli in the analog functional analysis. To evaluate the extent to which environmental events occurred at specified instances (preceding and following target behaviors) throughout the analysis, conditional probabilities were calculated (Anderson \& Long, in press; Lerman \& Iwata, 1993). Both Anderson and Long, and Lerman and Iwata coded some or all responses using a partial interval coding system, and calculated proportions on an interval-by-interval basis. In the current study, frequency data were coded for all responses, and proportions were thus calculated for each occurrence of a problem behavior or environmental event. 
Formulas used to calculate conditional probabilities are included in Table 3 . With the exception of the first event, correctly delivered prompts, two formulas were calculated for each environmental event. The first formula was used to determine the proportion of environmental events correctly delivered within $10 \mathrm{~s}$ before or after the problem behavior (event-based formula). This formula answers the question, "of all the times an environmental event (e.g., attention delivery) occurred, what proportion followed (or preceded) problem behavior?" The second formula displays the proportion of child responses preceded or followed by the environmental event within $10 \mathrm{~s}$ (behavior-based formula) and answers the question, "of all the instances of problem behavior, what proportion were preceded or followed by an environmental event?" Using attention delivery in the attention condition as an example, the results of the first formula indicate the proportion of all instances of attention delivery that followed problem behavior. If the attention condition is conducted properly, the resulting coefficient should be close to $100 \%$, indicating that attention delivery occurred only after occurrences of problem behavior. The second calculation determines the proportion of problem behavior that was followed by attention delivery (same or subsequent interval); the resulting coefficient should be close to $100 \%$, demonstrating that all or almost all instances of problem behavior were followed by attention delivery. Conditional probabilities were calculated for caregiver-conducted and experimenter-conducted sessions, and proportions obtained with caregivers as therapists were compared to the proportions obtained when experimenters conducted sessions.

To facilitate analysis of conditional probabilities, proportions obtained from each session conducted with a specific participant were averaged within conditions to obtain a mean proportion of occurrence for each environment-behavior relation. For example, the proportion of all problem behaviors that occurred in attention conditions and was followed by attention 
delivery was calculated. The following therapist behaviors were measured as a means of assessing procedural integrity: delivery of praise or attention; verbal, gestural, and physical prompts; tangible delivery and removal; and task delivery and removal (see Table 1 for operational definitions).

Measure of Caregiver Knowledge

Caregiver understanding of functional relations was measured before and after the caregiver was trained to conduct the analog functional analysis using the Reasons for Misbehavior Scale (RMS); (Weigle \& Scotti, 2000; see Appendix). The wording of the statements was slightly reworded from its original format; however, this should not have an impact on its validity. Caregivers were instructed to answer each item based on their personal experiences with their child and knowledge they had acquired about problem behaviors exhibited by persons with disabilities.

\section{Experimental Design and Procedure}

Prior to conducting the analog, two indirect methods of functional assessment were implemented: the scatterplot (Touchette et al., 1985) and the Functional Analysis Interview Form (FAI) (O'Neill, et al., 1989). The analog functional analysis, discussed below, was conducted using a multi-element design. To evaluate the effects of different therapists (i.e., caregiver versus experimenter), the multi-element design was embedded in a reversal design. The order of therapists conducting sessions was counterbalanced to control for possible order effects. For 2 participants, phases A and A' were conducted by caregivers, and Phase B was conducted by the experimenter. For the remaining two participants, phases A and A' were conducted by the experimenter and Phase B was conducted by the participant's caregiver. During experimenter conducted phases, several experimenters conducted the sessions. That is, the same experimenter 
always conducted the same condition for a specific child, and another experimenter might have conducted a different condition throughout the analog for the same child. For example, experimenter A might have conducted the attention condition for a child, experimenter B might have conducted the demand condition for the same child, and experimenter $\mathrm{C}$ might have conducted the tangible condition for the same child throughout the analog. Each experimenter also rotated through the play condition; thus, all experimenters conducted the play condition to control for experimenter effects. Within each phase, sessions were conducted until stability (using visual inspection) in responding was observed.

Caregiver training. Prior to beginning the assessment, written information was provided to caregivers regarding the purpose of a functional analysis and the conditions conducted. Next, caregivers were trained to implement each condition of the analog functional analysis. Training was accomplished via written instruction, observation of videotaped role-plays in which trained graduate and undergraduate students portrayed therapists and children, and rehearsal with feedback. Rehearsal and feedback were conducted with trained graduate students portraying a child and continued until caregivers responded appropriately at least $90 \%$ of the time during rehearsal of each session. (Appropriate responses are defined in Table 1). Once this criterion was met, caregivers began conducting the analog functional analysis.

Prior to conducting each session, caregivers were verbally reminded how to conduct the session. Additional feedback on caregiver responding occurred following each session conducted by caregivers throughout the analog analysis. Also, caregivers received coaching during the session if the procedure was not properly followed (e.g., during the tangible condition, the parent delivers attention following problem behavior) three times in succession. Coaching was provided using verbal prompts delivered by the experimenter. 
Experimenters were trained to conduct analog sessions via observation of actual and roleplayed sessions. Experimenters also participated in role-plays with the author prior to conducting the first session of each condition.

Scatterplot and Functional Analysis Interview Form. Prior to collection of baseline data, caregivers were asked to collect data for one week using a scatterplot form to gather information about environment-behavior relations and by completion of the FAI. Using the scatterplot, caregivers were to record the frequency of responding within 30-min intervals between 6:00 a.m. and 11:00 p.m. None of the caregivers collected scatterplot data for the entire week. The FAI (O’Neill et al., 1989) was used to operationally define problem behavior, to identify situations that often occasioned problem behavior, and to identify preferred items for use in the analog functional analysis.

Functional analysis. The analog functional analysis was based on procedures described by Iwata et al. (1982/1994). Conditions were conducted in a multielement design and condition order was randomly determined; however, the same condition was not run twice in succession. The following conditions were conducted: demand, attention, tangible, and play. During the demand condition, instructional tasks were presented to the participant by the therapist on a fixed-time (FT) 20-s schedule. A sequential three-step prompting sequence was used (verbal, gestural, and physical prompts). Compliance following a verbal or gestural prompt resulted in brief verbal praise (e.g. "Great job!). Any instances of problem behavior during task delivery were followed by a 20 -s time-out (escape) from tasks. No programmed consequences were delivered for problem behavior that occurred during the 20-s intertrial interval (ITI). The purpose of this condition was to test the hypothesis that problem behavior was maintained by escape from tasks. 
During the attention condition toys were available to the participant. The therapist was in the room and engaged in an activity (e.g., reading a magazine). Verbal attention (e.g., "Don't do that.") was delivered contingent on the occurrence of problem behavior (FR1 schedule). This condition was designed to test the hypothesis that problem behavior was maintained access to attention.

Prior to the tangible condition, the participant was provided with access to a preferred object (based on caregiver report and informal observation prior to conducting the analog analysis) for $2 \mathrm{~min}$. The preferred stimulus was removed at the onset of the session. Instances of problem behavior resulted in delivery of the tangible for $20 \mathrm{~s}$. No programmed consequences were delivered during the 20 -s period that tangibles were available. This condition was conducted to determine whether problem behavior was maintained by access to preferred activities or items.

The play condition was conducted as a control condition and was designed to serve as an "ideal situation" and to control for the presence of the therapist, the presence of preferred tangibles, and the absence of demands. In the play condition, the therapist was present in the room. The participant was provided with access to a variety of items, including stimuli used in the attention and tangible conditions. The therapist provided brief verbal attention (e.g., "You are doing a nice job playing.) on a FT 20-s schedule. If problem behavior occurred within $5 \mathrm{~s}$ of scheduled attention delivery, attention was withheld until five consecutive seconds without problem behavior passed. There were no programmed consequences for problem behavior.

Results and Discussion

For each participant, results of the analog functional analyses are depicted in Figures 1 through 4. Procedural integrity data are in Table 4. The results obtained with the RMS are shown in Table 5. 


\section{Brandon}

Results obtained with Brandon are depicted in Figure 1. The experimenter-conducted analysis occurred first with Brandon. In Phase A (experimenter conducted), problem behavior was most frequently observed in the demand condition $(M=2.5)$ and was consistently low in all other conditions. Brandon's rate of problem behavior in the demand condition was near the optimal level (i.e., 3 per minute); that is, Brandon's rate of responding was efficient given that each instance of problem behavior should result in a 20 -s escape interval. When his caregiver served as therapist (Phase B), rates of problem behavior were high in all conditions except the play condition. When the experimenter resumed as therapist (Phase A'), responding again occurred almost exclusively in the demand condition. Thus, results obtained with Brandon suggested different hypotheses of problem behavior depending on who conducted the analysis. Given that rates of responding in the presence of the experimenter were highest in the demand condition, it is suggested that responding was maintained by escape or avoidance of tasks. As a result of high rates of responding in all conditions except the play condition in the analysis conducted by his caregiver, it is suggested that responding was maintained by access to attention and tangibles and escape from tasks.

Procedural integrity data obtained in the analysis with Brandon are in Table 4. Overall, Brandon's mother conducted the analog functional analysis with a high degree of integrity. Proportions ranged from $87 \%$ to $100 \%$. Proportions were comparable to those attained in experimenter-conducted conditions suggesting that Brandon's caregiver implemented the procedures similarly to the experimenters.

Scatterplot data were not obtained with Brandon as his teacher had been collecting frequency data prior to participation in the study, and she stated that she preferred to continue collecting 
such data rather than using the scatterplot form. Brandon's teacher collected data for 9 days during which time problem behavior occurred most often during work activities such as circle time, group activities, and one-to-one instruction. Results suggested that problem behavior occurring in the classroom might be maintained by access to attention and tangibles and also by escape or avoidance from tasks. It was difficult to draw conclusions about maintaining consequences because multiple consequences typically were delivered following problem behavior (e.g., placing Brandon in time-out, thus, removing requests, while simultaneously discussing his misbehavior with him). Therefore, it was not possible to determine which consequence or consequences maintained problem behavior.

\section{Donna}

Results obtained with Donna are depicted in Figure 2. The caregiver analysis was conducted first with Donna. When Donna's caregiver served as therapist in the first phase, problem behavior was observed most frequently during the attention condition $(M=8.3)$, but problem behavior also occurred in the demand condition $(M=3.4)$. During sessions conducted with experimenters, rates of problem behavior were high in the attention and demand conditions; however, rates were highest in the demand condition $(M=9.8)$. In fact, rates were much higher than the optimal level of responding (i.e., 3 per minute) suggesting that Donna might have been engaging in problem behavior for reasons other than just escape. Responding in the attention condition was somewhat variable, but generally occurred at high rates $(M=7.4)$. In the demand condition conducted by the experimenter, Donna frequently engaged in problem behavior during escape intervals, which may account for higher rates of problem behavior in the experimenterconducted phase than the caregiver-conducted phase. One possible explanation for this is that experimenters were more likely to block instances of problem behavior, thus, giving Donna 
some attention. Donna's caregiver rarely blocked instances of problem behavior. Throughout all conditions conducted by experimenters, it was anecdotally observed that Donna's intensity of problem behavior was higher; that is, Donna hit her head and bit her head much harder. When Donna's caregiver resumed the role of therapist (Phase A'), Donna emitted high rates of problem behavior during the initial attention session. Interestingly, responding in the attention condition decreased substantially in subsequent attention sessions. Anecdotally, this may have occurred because Donna's grandmother began to ignore Donna's problem behavior at home after completion of the experimenter-conducted assessment. It is possible that the effects of the intervention generalized to the attention condition of the analog functional analysis. Responding in the demand condition was relatively stable across the final caregiver-conducted phase $(M=$ 6.1). Taken together, results obtained with Donna suggested that problem behavior was maintained by access to attention and escape from demands. Due to rates of responding that occurred at a more than optimal level in the demand condition, further evaluation of events that occurred during the escape interval in the presence of the experimenter is warranted to determine precisely what is maintaining Donna's problem behavior, attention or escape.

Procedural integrity data obtained in the analysis with Donna are in Table 4. Overall, Donna's grandmother conducted the analog functional analysis with a high degree of integrity. Proportions ranged from $83 \%$ to $100 \%$, which were comparable to proportions attained in experimenter-conducted conditions.

Scatterplot data were collected by Donna's grandmother for four days. SIB reliably occurred upon awakening and prior to meals. When problem behavior occurred upon awakening, her grandmother turned music on and self-injury ceased. Anecdotally, Donna's grandmother reported that she believed Donna often exhibited SIB when she was hungry and therefore 
frequently fed her when SIB occurred. She reported that this resulted in suppression of SIB. Information from the scatter plot suggested problem behavior might be evoked by tangible deprivation and maintained by access to tangible items; however, these functional relations were not observed in the analog. Importantly, Donna's grandmother also provided Donna with attention when she exhibited SIB, and anecdotal observations suggested that attention was provided almost every time SIB occurred. Although it is possible that tangible and food deprivation evoked SIB, and that delivery of food or tangibles resulted in decreases in SIB, it seems likely that SIB also was maintained by access to adult attention. This hypothesis is further supported by the decrease in SIB observed when Donna's grandmother began ignoring Donna's SIB in the home.

\section{Natalie}

Figure 3 displays the results obtained with Natalie. Although responding initially was somewhat variable in the first phase (caregiver-conducted), after several sessions responding occurred most often in the attention condition. Problem behavior occurred an average of 5.8 times per minute in the attention condition. In the attention condition of phase B (experimenterconducted) and phase A' (caregiver-conducted), problem behavior occurred an average of 6.4 times per minute and 8.5 times per minute, respectively. Although responding occurred at high rates during some tangible sessions conducted in Phase A, responding gradually decreased in this condition. Also, problem behavior in the tangible condition was equally likely to occur when Natalie had access to tangibles, suggesting that problem behavior may have been evoked by the absence of attention (attention maintained responding). Thus, elevated rates of problem behavior in the attention condition across all phases of the analysis, suggest that problem behavior was maintained by access to attention. 
Procedural integrity data obtained in the analysis with Natalie are in Table 4. Overall, Natalie's teacher conducted the analog functional analysis with a high degree of integrity. Proportions ranged from $83 \%$ to $100 \%$, which were comparable to proportions obtained in the experimenter-conducted functional analysis.

Scatterplot data were collected for 5 days with Natalie. Problem behavior occurred almost continuously throughout the day and no clear patterns could be discerned. Problem behavior often occurred at especially high levels when meals were brought into the room. At this time, the other students left the room, and Natalie was not allowed to begin eating until everyone had left the room. This suggests that problem behavior might have been evoked by the presence of tangible items (food) that were not immediately available. Importantly, anecdotal observations suggested that problem behavior in this situation was not followed by food delivery but rather by 1:1 adult attention. Anecdotally, Natalie's teacher reported that problem behavior occurred as well during group activities (and was followed by attention from adults and peers) and during work intervals. When problem behavior occurred during work intervals, Natalie often was placed in time-out during which an aide or teacher sat with and attended to her. Thus, the scatter plot, when combined with information obtained anecdotally and through direct observation, also suggests that problem behavior was maintained by access to attention.

\section{Shawn}

Results obtained with Shawn are displayed in Figure 4. During the first experimenterconducted phase (Phase A), problem behavior occurred almost exclusively in the attention condition $(M=4.7)$. When Shawn's caregiver served as therapist, responding increased in the attention condition $(M=10.8)$ but occurred as well in tangible condition $(\mathrm{M}=1.9)$. Problem behavior was occurring at near optimal levels (i.e., 3 per minute) in the tangible condition 
suggesting that Shawn was engaging in problem behavior to gain access to preferred items. In Phase A' (experimenter-conducted), responding occurred almost exclusively in the attention condition $(M=4.4)$. As a result of high rates of problem behavior in the attention condition when experimenters conducted the analysis, problem behavior was likely maintained by attention; however, when Shawn's mother conducted the analysis, problem behavior occurred at high rates in both the attention and tangible conditions suggesting problem behavior was maintained by access to attention and access to tangibles.

Procedural integrity data obtained in the analysis with Shawn are in Table 4. Overall, Shawn's mother conducted the analog functional analysis with a high degree of integrity. With one exception (event-based proportion in the tangible removal proportion), proportions ranged from $81 \%$ to $100 \%$, which were comparable to proportions obtained in the experimenterconducted functional analysis. The lower proportion (43\%) in the tangible removal formula was due to the Shawn's mother giving him access to the tangibles for longer than $20 \mathrm{~s}$. This likely contributed to lower than optimal rates of responding in this condition. Specifically, Shawn was given 30 -s access to preferred items lowering the optimal rate of responding to 2 per minute further providing support for a hypothesis that access to tangibles maintains Shawn's problem behavior. Proportions for tangible removal were the lowest for all caregivers in the study suggesting that more training might have been necessary.

Scatterplot data were collected for 3 days with Shawn. Unfortunately, his caregiver collected data for only about 2-3 hours per day. Problem behavior occurred most often when direct attention was not available (e.g., caregiver was on the telephone or working with his sister). 


\section{Reasons for Misbehavior Scale}

Results from the RMS are depicted in Table 5. The order of items has been changed such that items that identify functional reasons for problem behavior (e.g., escaping demands, access to attention) are grouped together followed by items that identify nonfunctional explanations for problem behavior. A score of "5" means that the rater strongly agreed and a score of "1" means that the rater strongly disagreed. A paired samples t-test was conducted on the data for the preand post- scores divided into functional and nonfunctional groups. A .05 alpha level was used for all statistical tests. Significant results were obtained when pre nonfunctional and post nonfunctional scores were analyzed $[\mathrm{t}(2)=8.660, \mathrm{p}<.02]$ suggesting that caregivers were less likely to endorse nonfunctional items following participation in the study. Analysis of pre functional and post functional scores were not significant $[\mathrm{t}(2)=3.051, \mathrm{p}=.09]$; however, caregivers were most likely to endorse environmental reasons for behavior prior to participation in the study, which might account for the results. Significant results also were found when comparing pre functional and non functional scores $[\mathrm{t}(2)=9.377, \mathrm{p}<.01]$ and post functional and nonfunctional scores $[\mathrm{t}(2)=12.785, \mathrm{p}<.01]$. These results demonstrate that caregivers were more likely to agree with functional reasons for behavior prior to and following participation in the study.

\section{General Discussion}

It has been suggested that inclusion of antecedent variables in functional analyses may result in better predictions of variables maintaining problem behavior. In the current study, the role of caregivers as therapists in the analog functional analysis was examined by comparing caregiverconducted analyses to experimenter-conducted analyses. Differential patterns of responding were observed when the analog functional analysis was conducted by caregivers versus experimenters 
for three of four participants. For three participants (Brandon, Donna, and Shawn), different functional relations were observed depending on who conducted the analysis. Also, for both Donna and Shawn, response rates were differentiated across assessments. For Donna, in the presence of the experimenter, responding occurred at higher rates in the demand condition and at lower rates overall in the attention condition than was observed when her caregiver conducted the analog. For Shawn, in the presence of his caregiver, responding occurred at higher rates in the attention and tangible conditions. These results are important because they illustrate that the presence or absence of variables present in the environment - the presence or absence of a caregiver in this case — affected hypotheses derived about functional relations for two of four participants and response frequency for one participant.

There are several possible explanations for the differential patterns of responding observed in the presence of the caregiver for three of four participants. First, caregivers might serve as discriminative stimuli for problem behavior. Given that caregivers have a greater history with the individual, it is reasonable to conclude that caregivers have been differentially paired with various consequences. For example, problem behavior emitted by an individual in the presence of his caregiver may result in attention delivery; thus, the individual has learned that in the engaging in problem behavior in the presence of his caregiver is likely to result in attention. Future research should examine the extent to which the presence of certain caregivers is discriminative for delivery or removal of specific consequences. One way this might be completed is to conduct a descriptive assessment (e.g., structured descriptive assessment; Anderson and Long, in press) before conducting the analog to determine if environmentbehavior relations are observed in the natural environment. 
Second, establishing operations may play a role. That is, caregivers (or experimenters) may alter the effectiveness of the reinforcer making the behavior more or less likely to occur. For example, attention from a caregiver may be more reinforcing than attention from a relative stranger. Conversely, escape from demands presented by a stranger may be reinforcing because interaction with that individual is not reinforcing; while on the contrary, escape from demands presented by a caregiver is not reinforcing because escape from demands is equated with removal of that individual's attention.

The results obtained in this study also suggest that caregivers can be trained to implement analog conditions with reasonable integrity (greater than $80 \%$ ) following a relatively brief training (approximately 2 hours). Integrity data collected on the first several sessions conducted by caregivers tended to be lower, possibly contributing to the lower percentages for caregivers than for experimenters. For example, Brandon's caregiver tended to give attention plus escape in the first few minutes of the first demand session. Caregivers usually made errors in the first few minutes of the first session but quickly improved and were less likely to make mistakes in subsequent sessions. These findings are similar to those of Iwata et al. (2000) who found that college students could be trained to conduct analog conditions in approximately 2 hours. In the Iwata et al. study, training consisted of written materials, videotaped role-plays, and quizzes. Participants in the Iwata et al. study conducted all conditions with at least 95\% accuracy, which is somewhat higher than the accuracy achieved in the current study. One reason for this is that it may be more difficult to change the way a caregiver responds to her child than to teach an adult to work with an unfamiliar individual. Further examination into training caregivers is warranted given the results of this study. 
Examination of caregiver knowledge of functional explanations of problem behavior suggest that training caregivers to conduct analog conditions did have some effect on their knowledge of events triggering problem behavior. However, it would be interesting to examine how caregivers' knowledge is impacted after an intervention for problem behavior has been implemented. Anecdotally, it was observed that caregivers tended to understand and generalize functional explanations of problem behavior after the intervention was implemented rather than prior to the implementation of the treatment. This may have occurred because caregivers saw behavior change in a desirable way following an intervention linked directly to the functional analysis they participated in. Future research is needed to examine caregiver's knowledge of functional relations. This is important because it seems likely that caregivers would be more likely to implement an intervention if they understood the rational behind it. That is, if they understood the reasons why their child emitted problem behavior.

Results of this study further support the results of Ringdahl and Sellers, and Sasso and colleagues; that is, caregivers appear to be an important variable to consider when conducting an analog functional analysis. However, there are several limitations to the current study. First, the order in which the caregivers and experimenters served as therapists, while random, could have contributed to the findings. Specifically, the two higher functioning participants (Brandon and Shawn) encountered the same order of therapists (i.e., experimenter, caregiver, experimenter) and were the only participants to display different functions of problem behavior across therapists. Whether this was due to the participant's cognitive level or to order effects cannot be determined. Further research is needed to determine if higher functioning individuals exhibit different functions of problem behavior as a function of therapist. 
Second, treatment data based on the results of the analog functional analyses were not collected. Therefore, it cannot be determined which phase of results (caregiver versus experimenter) would result in the most effective treatment, particularly for the two participants with different patterns of responding. It is necessary to systematically evaluate treatments based on the results of each phase of the analysis to determine which resulted in the greatest reduction in problem behavior. By doing so, the extent to which treatment integrity is enhanced by the inclusion of caregivers in the analog could be demonstrated. This would serve to further enhance the external validity of the analog functional analysis. For example, it would be critical to systematically evaluate the use of time-out and escape extinction for problem behavior hypothesized to be maintained by access to attention and escape from tasks. Hence, future research should evaluate treatment efficacy based on the results from each analog, the caregiverconducted and the experimenter-conducted, to determine which one produces better reduction in problem behavior.

Finally, results from the scatterplot and FAI and the analog functional analyses did not always suggest similar functions of problem behavior. This may be due to the limited amount of data for some participants. Also, the scatter plot does not directly identify potential environmentbehavior relations. Although it is useful for identifying patterns of behavior triggered by stimulus conditions such as time of day and specific locations (e.g., school, home), specific antecedent events can be hypothesized only if the schedule remains constant across days during which data are collected. Furthermore, information about consequences that might be maintaining behavior is not provided by the scatter plot. With regards to the FAI, caregivers often have a difficult time recalling what occurs prior to problem behavior. Specifically, caregivers are likely to report that problem behavior occurred out of the blue. Also, information obtained from the FAI is recalled 
by the caregiver and thus may not be accurate. Consequently, future research should compare results obtained from experimenter and caregiver-conducted analyses to functional analyses conducted in the natural environment. In doing so, the extent to which the experimenterconducted analysis suggests similar patterns of responding to those observed in the natural environment could be evaluated. Thus, future research should evaluate the validity of including caregivers in analog functional analyses.

Given the results of this study, it seems that inclusion of caregivers in the analog functional analysis is a critical variable to further evaluate. Better hypotheses of problem behavior and thus better treatment recommendations might result from caregiver inclusion. Furthermore, better treatment integrity might be obtained as a result of caregiver participation in the analog functional analysis because of the impact on their knowledge of functional explanations of problem behavior. 


\section{References}

Anderson, C. M., Freeman, K. A., \& Scotti, J. R. (1999). Evaluation of the generalizability (reliability and validity) of analog functional assessment methodology. Behavior Therapy, $30,31-50$.

Anderson, C. M., \& Long, E. (in press). Evaluation of structured functional assessment methodology. Journal of Applied Behavior Analysis.

Asmus, J. M., Wacker, D. P., Harding, J., Berg, W. K., Derby, K. M., \& Kocis, E. (1999). Evaluation of antecedent stimulus parameters of the treatment of escape-maintained aberrant behavior. Journal of Applied Behavior Analysis, 32, 495-513.

Bijou, S. W., Peterson, R. F., \& Ault, M. H. (1968). A method to integrate descriptive and experimental fields studies at the level of data and empirical concepts. Journal of Applied Behavior Analysis, 1, 175-191.

Carr, E. G., Yarbrough, S. C., \& Langdon, N. A. (1997). Effects of idiosyncratic stimulus variables on functional analysis outcomes. Journal of Applied Behavior Analysis, 30, 673686.

Catania, A. C. (1998). Learning (4 ${ }^{\text {th }}$ ed.). Upper Saddle River, NJ: Prentice-Hall.

Cooper, L. J., Wacker, D. P., Sasso, G. M., Reimers, T. M., \& Donn, L. K. (1990). Using caregivers as therapists to evaluate the appropriate behavior of their children: Application to a tertiary diagnostic clinic. Journal of Applied Behavior Analysis, 23, 285-296.

Cooper, L. J., Wacker, D. P., Thursby, D., Plagmann, L. A., Harding, J., Millard, T., et al. (1992). Analysis of the effects of task preferences, task demands, and adult attention on child behavior in outpatient and classroom settings. Journal of Applied Behavior Analysis, $25,823-840$. 
Derby, K. M., Wacker, D. P., Berg, W., DeRand, A., Ulrich, S., Asmus, J., et al. (1997). The long-term effects of functional communication training in home settings. Journal of Applied Behavior Analysis, 30, 507-531.

Derby, K. M., Wacker, D. P., Sasso, G., Steege, M., Northup, J., Cigrand, K., et al. (1992). Brief functional assessment techniques to evaluate aberrant behavior in an outpatient setting: A summary of 79 cases. Journal of Applied Behavior Analysis, 25, 713-721.

Fisher, W. W., O'Connor, J. T., Kurtz, P. F., DeLeon, I. G., \& Gotjen, D. L. (2000). The effects of noncontingent delivery of high- and low-preference stimuli on attention-maintained destructive behavior. Journal of Applied Behavior Analysis, 33, 79-83.

Griffin, J. C., Locke, B. J., \& Landers, W. F. (1975). Manipulation of potential punishment parameters in the treatment of self-injury. Journal of Applied Behavior Analysis, 8, 458.

Hagopian, L., P., Fisher, W. W., Sullivan, M. T., Acquisto, J., \& LeBlanc, L. A. (1998). Effectiveness of functional communication training with and without extinction and punishment: A summary of 21 inpatient cases. Journal of Applied Behavior Analysis, 31, 211-235.

Halle, J. W., \& Spradlin, J. E. (1993). Identifying stimulus control of challenging behavior. In J. Reichele \& D. Wacker (Eds.), Communicative alternatives to challenging behavior (pp. 83109). Baltimore, MD: Brookes.

Iwata, B. A., Dorsey, M., Slifer, K., Bauman, K., \& Richman, G. (1994). Toward a functional analysis of self-injury. Journal of Applied Behavior Analysis, 27, 197-209. (Reprinted from Analysis and Intervention in Developmental Disabilities, 2, 3-20, 1982)

Iwata, B. A., Pace, G. M., Cowdery, G. E., \& Miltenberger, R. G. (1994). What makes extinction work: An analysis of procedural form and function. Journal of Applied Behavior Analysis, 
27, 134-144.

Iwata, B. A., Pace, G. M., Dorsey, M. F., Zarcone, J. R., Vollmer, T. R., Smith, R. G., et al. (1994). The functions of self-injurious behavior: An experimental-epidemiological analysis. Journal of Applied Behavior Analysis, 27, 215-240.

Iwata, B. A., Vollmer, T. R., \& Zarcone, J. R. (1990). The experimental (functional) analysis of behavior disorders: Methodology, applications, and limitations. In A. C. Repp \& N. N. Singh (Eds.), Perspectives on the use of nonaversive and aversive interventions for persons with developmental disabilities (pp. 301-330). Sycamore, IL: Sycamore.

Iwata, B. A., Vollmer, T. R., Zarcone, J. R, \& Rodgers, T. A. (1993). Treatment classification and selection based on behavioral function. In R. Van Houten \& S. Axelrod (Eds.), Behavior analysis and treatment (pp. 102-125), New York: Plenum.

Iwata, B. A., Wallace, M. D., Kahng, S., Lindberg, J. S., Roscoe, E. M., Conners, J., et al. (2000). Skill acquisition in the implementation of functional analysis methodology. Journal of Applied Behavior Analysis, 33, 181-194.

Kahng, S., \& Iwata, B. A. (1999). Correspondence between outcomes of brief and extended functional analyses. Journal of Applied Behavior Analysis, 32, 149-159.

Lalli, J. S., Casey, S. D., \& Kates, K. (1997). Noncontingent reinforcement as treatment for severe problem behavior: Some procedural variations. Journal of Applied Behavior Analysis, $30,127-137$.

Lerman, D. C., \& Iwata, B. A. (1993). Descriptive and experimental analysis of variables maintaining self-injurious behavior. Journal of Applied Behavior Analysis, 26, 293-319.

Mace, F. C., Hock, M. L., Lalli, J. S., West, B. J., Belfiore, P., Pinter, E., et al. (1988). Behavioral momentum in the treatment of noncompliance. Journal of Applied Behavior 
Analysis, 21, 123-141.

Mace, F. C., Lalli, J. S., Pinter Lalli, E., \& Shea, M. C. (1993). Functional analysis and treatment of aberrant behavior. In R. Van Houten \& S. Axelrod (Eds.), Behavior analysis and treatment (pp. 102-125), New York: Plenum.

Marcus, B. A., \& Vollmer, T. R. (1996). Combining noncontingent reinforcement and differential reinforcement schedules as treatment for aberrant behavior. Journal of Applied Behavior Analysis, 29, 43-51.

McComas, J., Hoch, H., Paone, D., \& El-Roy, D. (2000). Escape behavior during academic tasks: A preliminary analysis of idiosyncratic establishing operations. Journal of Applied Behavior Analysis, 33, 479-493.

Michael, J. (1993). Establishing operations. The Behavior Analyst, 16, 191-206.

Northup, J., Wacker, D. P., Berg, W. K., Kelly, L., Sasso, G., \& DeRaad, A. (1994). The treatment of severe behavior problems in school settings using a technical assistance model. Journal of Applied Behavior Analysis, 27, 33-47.

Northup, J., Wacker, D., Sasso, G., Steege, M., Cigrand, K., Cook, J., et al. (1991). A brief functional analysis of aggressive and alternative behavior in an outclinic setting. Journal of Applied Behavior Analysis, 24, 509-522.

O’Neill, R. E., Horner, R. H., Albin, R. W., Storey, K., \& Sprague, J. R. (1989). The functional analysis interview. In R. H. Horner, J. L. Anderson, E. G. Carr, G. Dunlap, R. L. Koegel, \& W. Sailor (Eds.), Functional analysis: A practical assessment guide (pp. 10-23). Eugene: University of Oregon Press.

O’Reilly, M. F., Lancioni, G. E., King, L., Lally, G., \& Dhomhnaill, O. N. (2000). Using brief assessments to evaluate aberrant behavior maintained by attention. Journal of Applied 
Behavior Analysis, 33, 109-112.

Paisey, T. J., Whitney, R. B., \& Hislop, P. M. (1990). Client characteristics and treatment selection: Legitimate influences and misleading inferences. In A. C. Repp \& N. N. Singh (Eds.), Perspectives on the use of nonaversive and aversive interventions for persons with developmental disabilities (pp. 175-197). Sycamore, IL: Sycamore.

Pelios, L., Morren, J., Tesch, D., \& Axelrod, S. (1999). The impact of functional analysis methodology on treatment choice for self-injurious and aggressive behavior. Journal of Applied Behavior Analysis, 32, 185-195.

Piazza, C. C., Adelinis, J. D., Hanley, G. P., Goh, H., \& Delia, M. D. (2000). An evaluation of the effects of matched stimuli on behaviors maintained by automatic reinforcement. Journal of Applied Behavior Analysis, 33, 13-27.

Repp, A. C., Felce, D., \& Barton, L. E. (1988). Basing the treatment of stereotypic and selfinjurious behaviors on hypotheses of their causes. Journal of Applied Behavior Analysis, 21, 281-289.

Ringdahl, J. E., \& Sellers, J. A. (2000). The effects of different adults as therapists during functional analyses. Journal of Applied Behavior Analysis, 33, 247-250.

Sasso, G. M., Reimers, T. M., Cooper, L. J., Wacker, D., Berg, W., Steege, M., et al. (1992). Use of descriptive and experimental analyses to identify the functional properties of aberrant behavior in school settings. Journal of Applied Behavior Analysis, 25, 809-821.

Shirley, M. J., Iwata, B. A., Kahng, S., Mazaleski, J. L., \& Lerman, D. C. (1997). Does functional communication training compete with ongoing contingencies of reinforcement? An analysis during response acquisition and maintenance. Journal of Applied Behavior Analysis, 30, 93-104. 
Smith, R. G., \& Iwata, B. A. (1997). Antecedent influences on behavior disorders. Journal of Applied Behavior Analysis, 30, 343-375.

Smith, R. G., Iwata, B. A., Goh, H., \& Shore, B. A. (1995). Analysis of establishing operations for self-injury maintained by escape. Journal of Applied Behavior Analysis, 28, 515-535.

Touchette, P. E., MacDonald, R. F., \& Langer, S. N. (1985). A daily behavior log for identifying a stimulus control of problem behavior. Journal of Applied Behavior Analysis, 18, 343-351.

Van Camp, C. M., Lerman, D. C., Kelley, M. E., Roane, H. S., Contrucci, S. A., \& Vorndran, C. M. (2000). Further analysis of idiosyncratic antecedent influences during the assessment and treatment of problem behavior. Journal of Applied Behavior Analysis, 33, 207-221.

Vollmer, T. R., Iwata, B. A., Zarcone, J. R., Smith, R. G., \& Mazaleski, J. L. (1993). The role of attention in the treatment of attention-maintained self-injurious behavior: Noncontingent reinforcement and differential reinforcement of other behavior. Journal of Applied Behavior Analysis, 26, 9-21.

Vollmer, T. R., Marcus, B. A., \& Ringdahl, J. E. (1995). Noncontingent escape as treatment for self-injurious behavior maintained by negative reinforcement. Journal of Applied Behavior Analysis, 28, 15-26.

Weigle, K. L., \& Scotti, J. R. (2000). Effects of functional analysis information on ratings of intervention effectiveness and acceptability. Journal of the Association for Persons with Severe Handicaps, 25, 217-228.

Zarcone, J. R., Iwata, B. A., Smith, R. G., Mazaleski, J. L., \& Lerman, D. C. (1994).

Reemergence and extinction of self-injurious escape behavior during stimulus (instructional) fading. Journal of Applied Behavior Analysis, 27, 307-316. 


\begin{abstract}
Author Note
I express my appreciation to Cindy Anderson for her support and advice throughout the study and for her helpful review of earlier drafts of this paper. I would also like to thank Phil Chase and Joseph Scotti for helpful comments on earlier drafts of this paper. I would like to thank Ellen Fittro, Raina Hosey, and Meghan Moore for helping to conduct sessions and train caregivers. Finally, I would like to thank Chad Galuska for developing a program to analyze the procedural integrity data.
\end{abstract}


Appendix

Reasons for Misbehavior Scale

(Modified)

Below are listed a number of different reasons that caregivers, teachers and other professionals have given over the years to explain why individuals with physical/sensory, intellectual/academic, and emotional/psychological disabilities engage in a variety of problematic behaviors. These sorts of behaviors may include self-injury, stereotypic/repetitive behaviors, disruptive and destructive behaviors, physical aggression, and inappropriate social behaviors. For each possible reason, please rate how much you agree or disagree with the statements regarding why individuals with disabilities might engage in a problem behavior. These ratings are only your opinion. In making the ratings, you should consider your own personal experiences as a parent, educator, or service provider over the years.

Respond to the statements by circling the appropriate number on the following scale:

$\begin{array}{lllll}1 & 2 & 3 & 4 & 5 \\ \text { Strongly } & \text { Somewhat } & \text { Not Sure } & \text { Somewhat } & \text { Strongly } \\ \text { Disagree } & \text { Disagree } & & \text { Agree } & \text { Agree }\end{array}$

(1) One reason individuals with disabilities might engage in problematic behaviors is because they are bored and understimulated.
1
2
3
4
5

(2) One reason individuals with disabilities might engage in problematic behaviors is because they are mentally retarded or autistic and cannot control themselves.
1
2
3
45

(3) One reason individuals with disabilities might engage in problematic behaviors is because they intentionally try to annoy and irritate the people around them.
1
2
3
45

(4) One reason individuals with disabilities might engage in problematic behaviors is because they do not have any other way to communicate their needs.

$\begin{array}{lllll}1 & 2 & 3 & 4 & 5\end{array}$

(5) One reason individuals with disabilities might engage in problematic behaviors is because they are hungry or tired.
1
23
$4 \quad 5$

(6) One reason individuals with disabilities might engage in problematic behaviors is because they want access to leisure materials or food that they cannot have.
1
2
3
4
5 
(7) One reason individuals with disabilities might engage in problematic behaviors is because they have medical problems (e.g., are ill, in pain, menses have allergies).

$\begin{array}{lllll}1 & 2 & 3 & 4 & 5\end{array}$

(8) One reason individuals with disabilities might engage in problematic behaviors is because they are being ignored and want attention.

$\begin{array}{lllll}1 & 2 & 3 & 4 & 5\end{array}$

(9) One reason individuals with disabilities might engage in problematic behaviors is because they are emotionally disturbed or have psychiatric problems.

(10) One reason individuals with disabilities might engage in problematic behaviors is because they are evil and are possessed by demons.
1
2
3
4
5

(11) One reason individuals with disabilities might engage in problematic behaviors is because they are overstimulated by the people and activities around them.
1
2
3
4
5

(12) One reason individuals with disabilities might engage in problematic behaviors is because of the time of the year (e.g., seasonal changes).

$\begin{array}{lllll}1 & 2 & 3 & 4 & 5\end{array}$

(13) One reason individuals with disabilities might engage in problematic behaviors is because they are not receiving the appropriate medications to control their behavior.

$\begin{array}{lllll}1 & 2 & 3 & 4 & 5\end{array}$

(14) One reason individuals with disabilities might engage in problematic behaviors is because they have a biological, genetic, or neurological disorder that causes their behavior.

$\begin{array}{lllll}1 & 2 & 3 & 4 & 5\end{array}$

(15) One reason individuals with disabilities might engage in problematic behavior is because they are frustrated or angry.

$\begin{array}{lllll}1 & 2 & 3 & 4 & 5\end{array}$

(16) One reason individuals with disabilities might engage in problematic behavior is because they have difficulty accepting changes in their environment (such as staff, activities, or settings). $\begin{array}{lllll}1 & 2 & 3 & 4 & 5\end{array}$

(17) One reason individuals with disabilities might engage in problematic behavior is to get out of doing things they do not like or to escape from demands.
1
23
45

(18) One reason individuals with disabilities might engage in problematic behavior is because their parents have not appropriately disciplined them.
1
2
3
4
5 
(19) One reason individuals with disabilities might engage in problematic behaviors is because of the phase of the moon (e.g., full moon).

$\begin{array}{lllll}1 & 2 & 3 & 4 & 5\end{array}$

Please feel free to list as many other reasons that you can think of as to why persons with disabilities might engage in problematic behaviors. Please do this on the backside of this page. 
Table 1

Appropriate Responses by Caregiver During Analog Functional Analysis

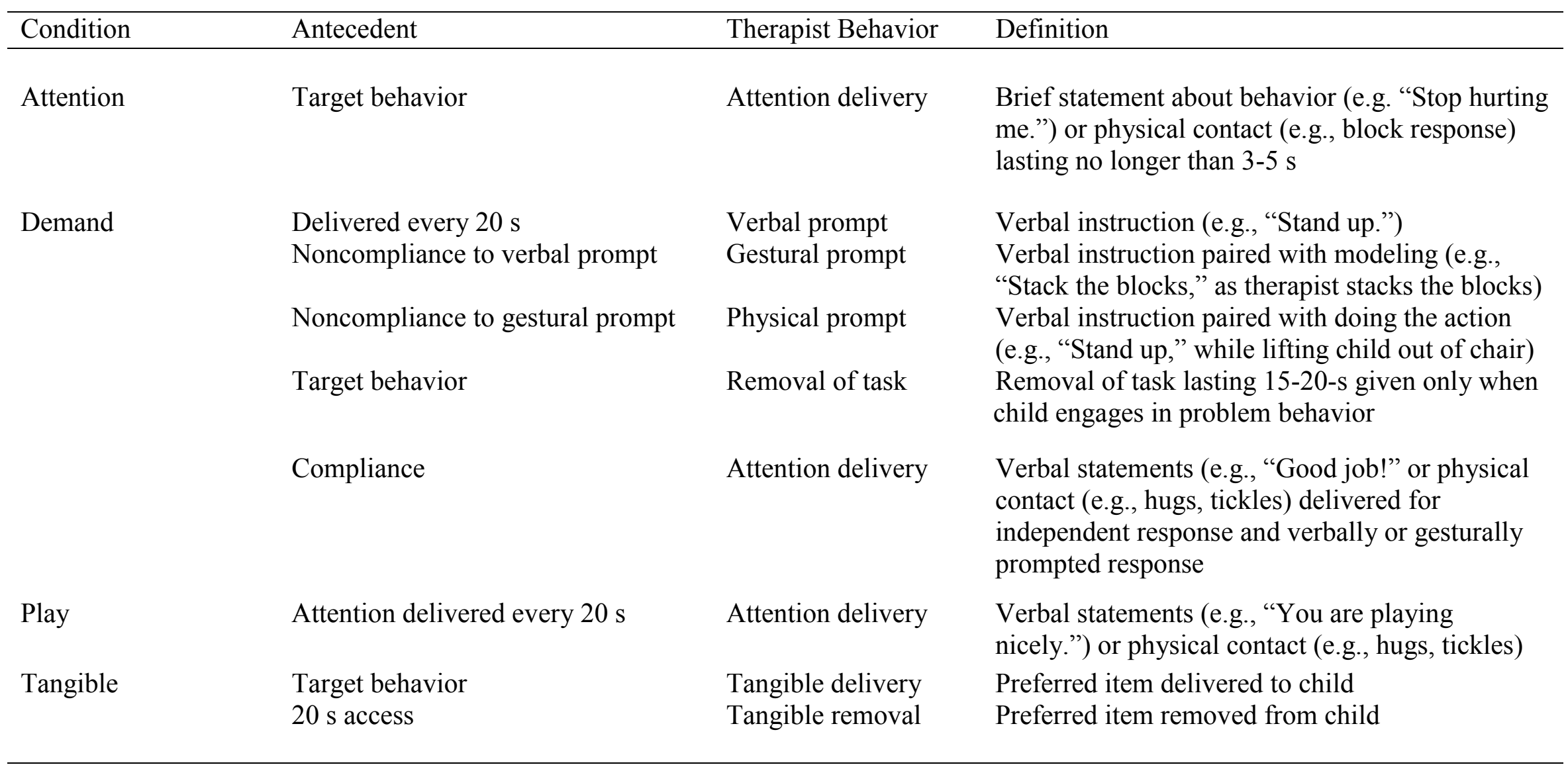


Table 2

Mean Agreement Scores for Child and Adult Responses

\begin{tabular}{|c|c|c|c|c|c|c|c|c|c|c|}
\hline Name & $\begin{array}{l}\text { Problem } \\
\text { behavior }\end{array}$ & Verbal & Gestural & Physical & Compliance & Attention & $\begin{array}{l}\text { Escape } \\
\text { delivery }\end{array}$ & $\begin{array}{l}\text { End of } \\
\text { escape } \\
\text { interval }\end{array}$ & $\begin{array}{l}\text { Tangible } \\
\text { delivery }\end{array}$ & $\begin{array}{l}\text { Tangible } \\
\text { removal }\end{array}$ \\
\hline Brandon & $\begin{array}{l}97 \% \\
\text { (range } \\
89 \%- \\
100 \% \text { ) }\end{array}$ & $\begin{array}{l}99 \% \\
\text { (range } \\
91 \%- \\
100 \% \text { ) }\end{array}$ & $\begin{array}{l}98 \% \\
\text { (range } \\
80 \%- \\
100)\end{array}$ & $\begin{array}{l}99 \% \\
\text { (range } \\
97 \%- \\
100 \% \text { ) }\end{array}$ & $\begin{array}{l}99 \% \\
\text { (range } \\
93 \%-100 \% \text { ) }\end{array}$ & $\begin{array}{l}97 \% \\
\text { (range } \\
92 \%- \\
100 \% \text { ) }\end{array}$ & $\begin{array}{l}99 \% \\
\text { (range } \\
93 \%- \\
100 \% \text { ) }\end{array}$ & $\begin{array}{l}99 \% \\
\text { (range } \\
90 \%- \\
100 \% \text { ) }\end{array}$ & $\begin{array}{l}99 \% \\
\text { (range } \\
93 \%- \\
100 \% \text { ) }\end{array}$ & $\begin{array}{l}99 \% \\
\text { (range } \\
95 \%- \\
100 \% \text { ) }\end{array}$ \\
\hline Donna & $\begin{array}{l}97 \% \\
\text { (range } \\
85 \%- \\
100 \% \text { ) }\end{array}$ & $\begin{array}{l}99 \% \\
\text { (range } \\
82 \%- \\
100 \% \text { ) }\end{array}$ & $\begin{array}{l}99 \% \\
\text { (range } \\
97 \%- \\
100 \% \text { ) }\end{array}$ & $\begin{array}{l}99 \% \\
\text { (range } \\
95 \%- \\
100 \% \text { ) }\end{array}$ & $\begin{array}{l}99 \% \\
\text { (range } \\
87 \%-100 \% \text { ) }\end{array}$ & $\begin{array}{l}97 \% \\
\text { (range } \\
83 \% \%^{-} \\
100 \% \text { ) }\end{array}$ & $\begin{array}{l}99 \% \\
\text { (range } \\
97 \%- \\
100 \% \text { ) }\end{array}$ & $\begin{array}{l}99 \% \\
\text { (range } \\
97 \% \%^{-} \\
100 \% \text { ) }\end{array}$ & $100 \%$ & $\begin{array}{l}99 \% \\
\text { (range } \\
97 \%- \\
100 \% \text { ). }\end{array}$ \\
\hline Natalie & $\begin{array}{l}96 \% \\
\text { (range } \\
65 \%- \\
100 \% \text { ) }\end{array}$ & $\begin{array}{l}99 \% \\
\text { (range } \\
88 \%- \\
100 \% \text { ) }\end{array}$ & $\begin{array}{l}98 \% \\
\text { (range } \\
95 \%- \\
100 \% \text { ) }\end{array}$ & $\begin{array}{l}99 \% \\
\text { (range } \\
97 \%- \\
100 \% \text { ) }\end{array}$ & $\begin{array}{l}99 \% \\
\text { (range } \\
91 \%-100 \% \text { ) }\end{array}$ & $\begin{array}{l}97 \% \\
\text { (range } \\
83 \%- \\
100 \% \text { ) }\end{array}$ & $\begin{array}{l}99 \% \\
\text { (range } \\
97 \%- \\
100 \% \text { ) }\end{array}$ & $\begin{array}{l}99 \% \\
\text { (range } \\
97 \%- \\
100 \% \text { ) }\end{array}$ & $\begin{array}{l}99 \% \\
\text { (range } \\
93 \% \%^{-} \\
100 \% \text { ) }\end{array}$ & $\begin{array}{l}99 \% \\
\text { (range } \\
95 \%- \\
100 \% \text { ) }\end{array}$ \\
\hline Shawn & $\begin{array}{l}97 \% \\
\text { (range } \\
72 \%- \\
100 \% \text { ) }\end{array}$ & $\begin{array}{l}97 \% \\
\text { (range } \\
84 \%- \\
100 \% \text { ) }\end{array}$ & $\begin{array}{l}99 \% \\
\text { (range } \\
93 \%- \\
100 \% \text { ) }\end{array}$ & $\begin{array}{l}99 \% \\
\text { (range } \\
97 \%- \\
100 \% \text { ) }\end{array}$ & $\begin{array}{l}97 \% \\
\text { (range } \\
83 \%-100 \% \text { ) }\end{array}$ & $\begin{array}{l}95 \% \\
\text { (range } \\
79 \%- \\
100 \% \text { ) }\end{array}$ & $\begin{array}{l}99 \% \\
\text { (range } \\
57 \% \%^{-} \\
100 \% \text { ) }\end{array}$ & $100 \%$ & $\begin{array}{l}99 \% \\
\text { (range } \\
97 \% \%^{-} \\
100 \% \text { ) }\end{array}$ & $\begin{array}{l}99 \% \\
\text { (range } \\
97 \% \%^{-} \\
100 \% \text { ) }\end{array}$ \\
\hline
\end{tabular}


Table 3

Formulas Used to Calculate Procedural Integrity

Proportion of correctly delivered prompts by caregivers

Proportion of escape intervals as a consequence of target behaviors

Proportion of attention delivered as a consequence of target behaviors

Proportion of tangibles delivered as a consequence of target behaviors

Proportion of tangibles removed
Number of correct prompts

Total number of prompts delivered

Number of escape deliveries that followed problem behavior Total number of escape deliveries

Number of escape deliveries that followed problem behavior Number of problem behaviors not occurring during an escape interval or ITI

Number of problem behaviors that preceded attention delivery Total number of attention deliveries

Number of problem behaviors that preceded attention delivery

Total number of problem behaviors

Number of problem behaviors that preceded tangible delivery Total number of tangible deliveries

Number of problem behaviors that preceded tangible delivery Number of problem behaviors not occurring during tangible delivery interval

Number of tangible removals following 15-25 s access

Total number of tangible removals

Number of tangible removals following $15-25$ s access

Number of tangible deliveries 
Table 4

Measures of Procedural Integrity

\begin{tabular}{|c|c|c|c|c|c|c|c|c|c|}
\hline \multirow[b]{2}{*}{ Variable } & & \multicolumn{2}{|c|}{$\underline{\text { Brandon }}$} & \multicolumn{2}{|c|}{ Donna } & \multicolumn{2}{|c|}{ Natalie } & \multicolumn{2}{|c|}{$\underline{\text { Shawn }}$} \\
\hline & & Caregiver & Experimenter & Caregiver & Experimenter & Caregiver & Experimenter & Caregiver & Experimenter \\
\hline Prompt & & $94 \%$ & $99 \%$ & $97 \%$ & $99 \%$ & $100 \%$ & $100 \%$ & $87 \%$ & $99 \%$ \\
\hline \multirow[t]{2}{*}{$\begin{array}{l}\text { Escape } \\
\text { delivery }\end{array}$} & $\begin{array}{l}\text { Event- } \\
\text { based }\end{array}$ & $100 \%$ & $100 \%$ & $100 \%$ & $100 \%$ & $100 \%$ & $100 \%$ & $100 \%$ & $100 \%$ \\
\hline & $\begin{array}{l}\text { Behavior- } \\
\text { based }\end{array}$ & $98 \%$ & $100 \%$ & $100 \%$ & $100 \%$ & $97 \%$ & $100 \%$ & $100 \%$ & $100 \%$ \\
\hline \multirow[t]{2}{*}{$\begin{array}{l}\text { Attention } \\
\text { delivery }\end{array}$} & $\begin{array}{l}\text { Event- } \\
\text { based }\end{array}$ & $97 \%$ & $100 \&$ & $100 \%$ & $100 \%$ & $83 \%$ & $100 \%$ & $100 \&$ & $100 \%$ \\
\hline & $\begin{array}{l}\text { Behavior- } \\
\text { based }\end{array}$ & $91 \%$ & $100 \%$ & $96 \%$ & $98 \%$ & $100 \%$ & $97 \%$ & $81 \%$ & $88 \%$ \\
\hline \multirow[t]{2}{*}{$\begin{array}{l}\text { Tangible } \\
\text { delivery }\end{array}$} & $\begin{array}{l}\text { Event- } \\
\text { based }\end{array}$ & $91 \%$ & $99 \%$ & $90 \%$ & $95 \%$ & $89 \%$ & $90 \%$ & $100 \%$ & $100 \%$ \\
\hline & $\begin{array}{l}\text { Behavior- } \\
\text { based }\end{array}$ & $100 \%$ & $100 \%$ & $100 \%$ & $100 \%$ & $98 \%$ & $99 \%$ & $100 \%$ & $100 \%$ \\
\hline \multirow[t]{2}{*}{$\begin{array}{l}\text { Tangible } \\
\text { removal }\end{array}$} & $\begin{array}{l}\text { Event- } \\
\text { based }\end{array}$ & $87 \%$ & $93 \%$ & $83 \%$ & $95 \%$ & $83 \%$ & $95 \%$ & $83 \%$ & $94 \%$ \\
\hline & $\begin{array}{l}\text { Behavior- } \\
\text { based }\end{array}$ & $87 \%$ & $93 \%$ & $83 \%$ & $95 \%$ & $83 \%$ & $95 \%$ & $43 \%$ & $94 \%$ \\
\hline
\end{tabular}


Table 5

Scores on the Reasons for Misbehavior Scale

\begin{tabular}{|c|c|c|c|c|c|c|c|}
\hline \multirow[b]{2}{*}{ Number } & \multirow[b]{2}{*}{ Item } & \multicolumn{2}{|c|}{$\underline{\text { Brandon }}$} & \multicolumn{2}{|c|}{ Donna } & \multicolumn{2}{|c|}{$\underline{\text { Shawn }}$} \\
\hline & & Pre & Post & Pre & Post & Pre & Post \\
\hline 1 & $\begin{array}{l}\text { because they have difficulty accepting } \\
\text { changes in their environment (such as } \\
\text { staff, activities, or settings). }\end{array}$ & 5 & 5 & 4 & 5 & 4 & 5 \\
\hline 2 & $\begin{array}{l}\text { because they are bored and } \\
\text { understimulated. }\end{array}$ & 1 & 2 & 4 & 4 & 4 & 4 \\
\hline 3 & $\begin{array}{l}\text { because they are being ignored and want } \\
\text { attention. }\end{array}$ & 2 & 4 & 4 & 5 & 4 & 5 \\
\hline 4 & $\begin{array}{l}\text { to get out of doing things they do not like } \\
\text { or to escape from demands }\end{array}$ & 5 & 5 & 4 & 5 & 4 & 5 \\
\hline 5 & $\begin{array}{l}\text { because they do not have any other way } \\
\text { to communicate their needs. }\end{array}$ & 5 & 5 & 5 & 5 & 3 & 4 \\
\hline 6 & $\begin{array}{l}\text { because they want access to leisure } \\
\text { materials or food that they cannot have. }\end{array}$ & 4 & 4 & 2 & 3 & 4 & 5 \\
\hline 7 & because they are hungry or tired. & 4 & 4 & 5 & 5 & 3 & 4 \\
\hline 8 & $\begin{array}{l}\text { because they are overstimulated by the } \\
\text { people and activities around them. }\end{array}$ & 5 & 4 & 5 & 4 & 5 & 5 \\
\hline 9 & $\begin{array}{l}\text { because they have medical problems } \\
\text { (e.g., are ill, in pain, menses have } \\
\text { allergies). }\end{array}$ & 5 & 5 & 5 & 5 & 3 & 3 \\
\hline 10 & $\begin{array}{l}\text { because they are not receiving the } \\
\text { appropriate medications to control their } \\
\text { behavior. }\end{array}$ & 3 & 3 & 3 & 3 & 3 & 1 \\
\hline 11 & $\begin{array}{l}\text { because they are emotionally disturbed or } \\
\text { have psychiatric problems. }\end{array}$ & 4 & 2 & 3 & 3 & 3 & 3 \\
\hline
\end{tabular}


Table 5 (continued)

\begin{tabular}{|c|c|c|c|c|c|c|c|}
\hline \multirow[b]{2}{*}{ Number } & \multirow[b]{2}{*}{ Item } & \multicolumn{2}{|c|}{ Brandon } & \multicolumn{2}{|c|}{ Donna } & \multicolumn{2}{|c|}{$\underline{\text { Shawn }}$} \\
\hline & & Pre & Post & Pre & Post & Pre & Post \\
\hline 12 & $\begin{array}{l}\text { because they have a biological, genetic, } \\
\text { or neurological disorder that causes their } \\
\text { behavior. }\end{array}$ & 5 & 5 & 4 & 4 & 3 & 3 \\
\hline 13 & because they are frustrated or angry. & 5 & 5 & 5 & 5 & 4 & 5 \\
\hline 14 & $\begin{array}{l}\text { because they are mentally retarded or } \\
\text { autistic and cannot control themselves. }\end{array}$ & 5 & 3 & 4 & 5 & 4 & 2 \\
\hline 15 & $\begin{array}{l}\text { because their caregivers have not } \\
\text { appropriately disciplined them. }\end{array}$ & 1 & 1 & 2 & 1 & 1 & 1 \\
\hline 16 & $\begin{array}{l}\text { because they intentionally try to annoy } \\
\text { and irritate the people around them }\end{array}$ & 1 & 1 & 2 & 1 & 5 & 4 \\
\hline 17 & $\begin{array}{l}\text { because of the time of the year (e.g., } \\
\text { seasonal changes). }\end{array}$ & 1 & 1 & 4 & 3 & 4 & 4 \\
\hline 18 & $\begin{array}{l}\text { because of the phase of the moon (e.g., } \\
\text { full moon). }\end{array}$ & 1 & 1 & 3 & 1 & 3 & 2 \\
\hline 19 & $\begin{array}{l}\text { because they are evil and are possessed } \\
\text { by demons. }\end{array}$ & 1 & 1 & 3 & 1 & 1 & 1 \\
\hline
\end{tabular}




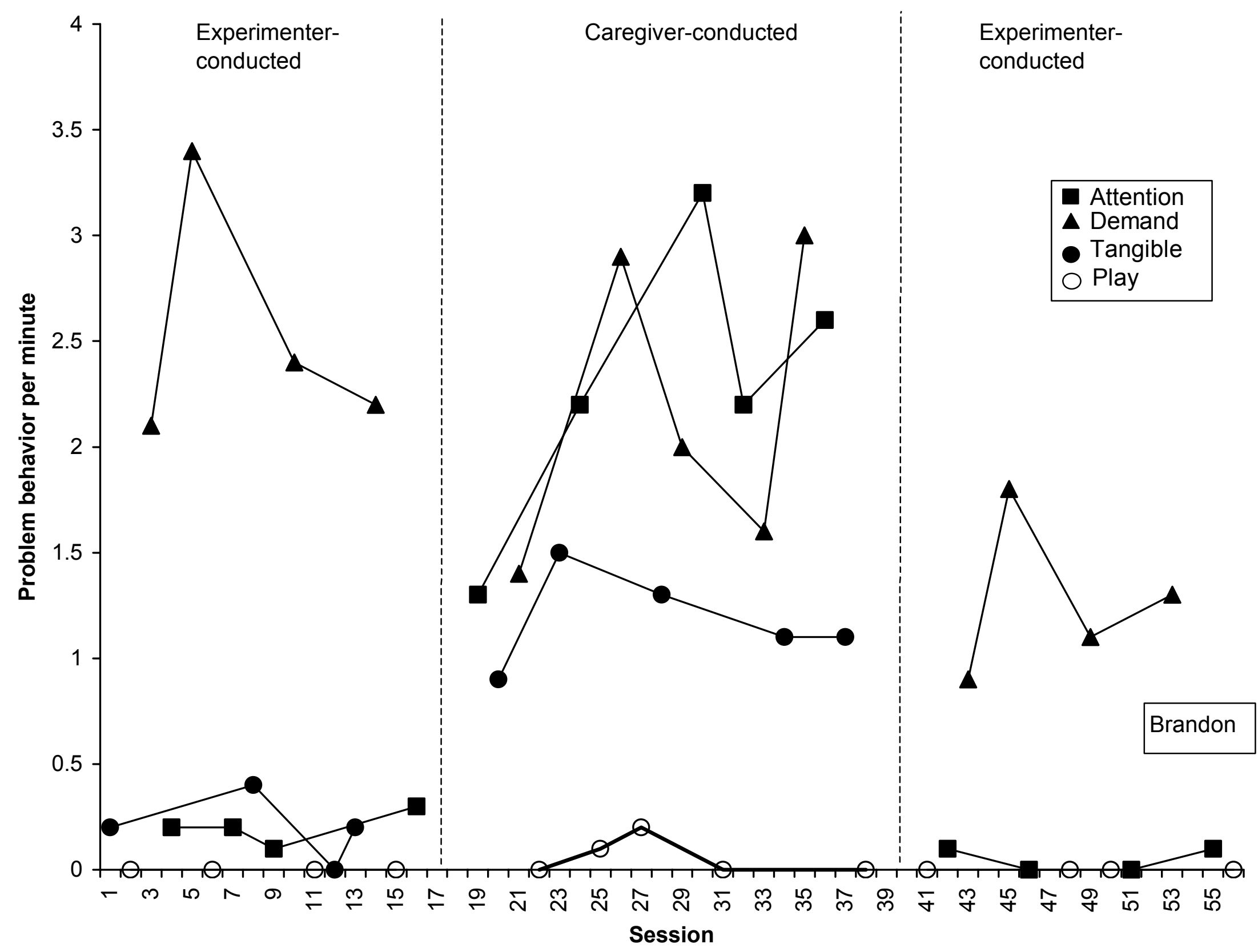


Therapists in the Analog 50

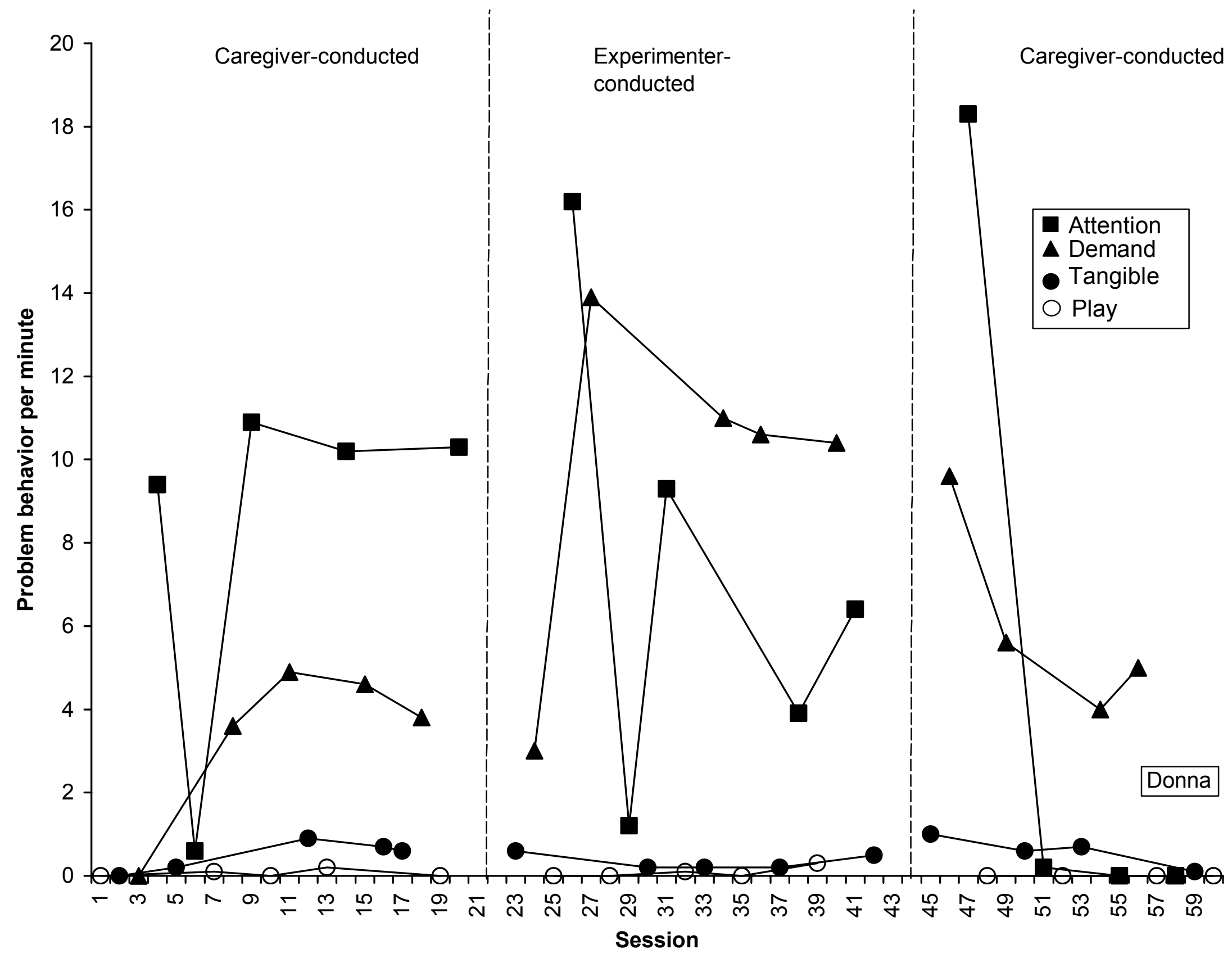


Therapists in the Analog 51

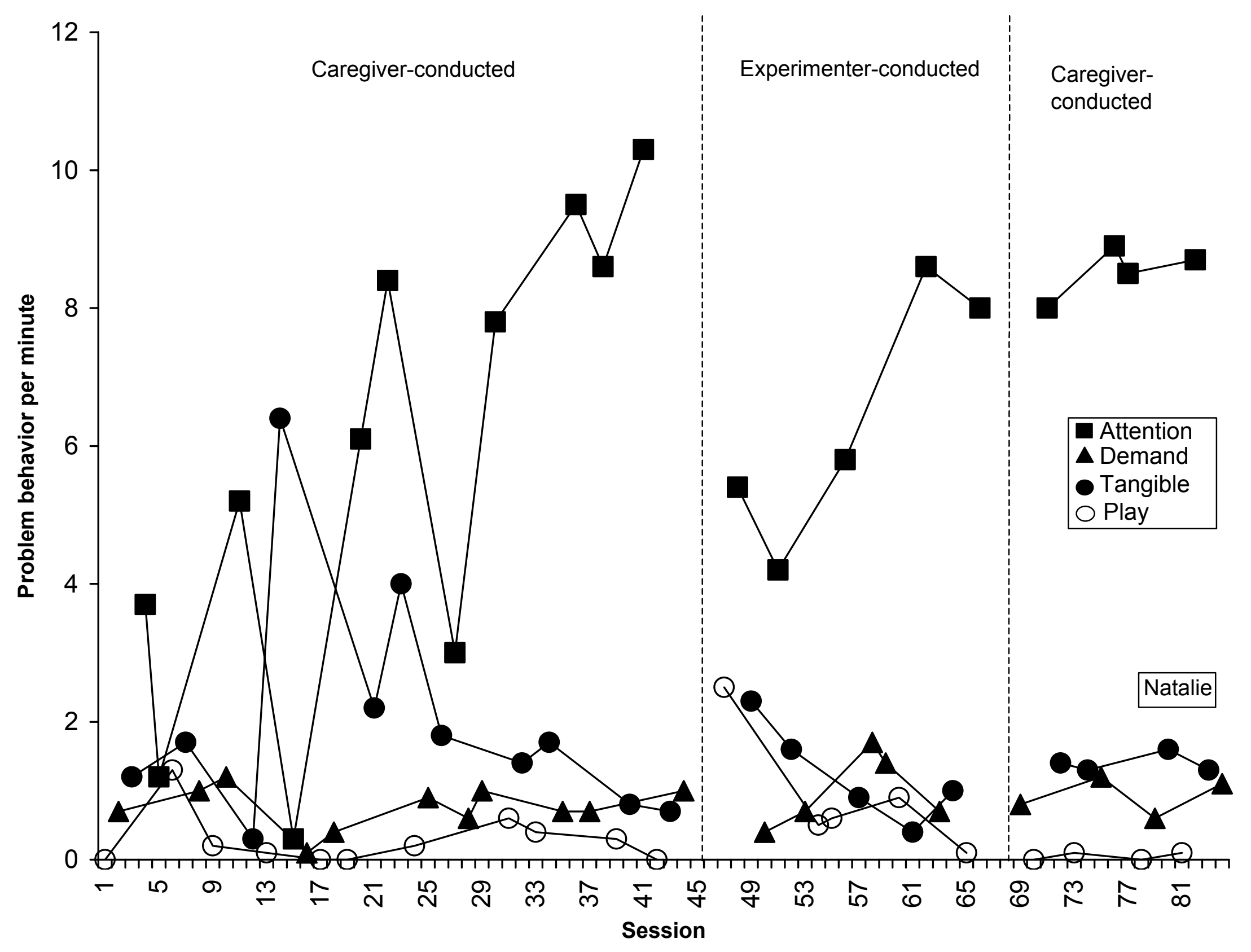




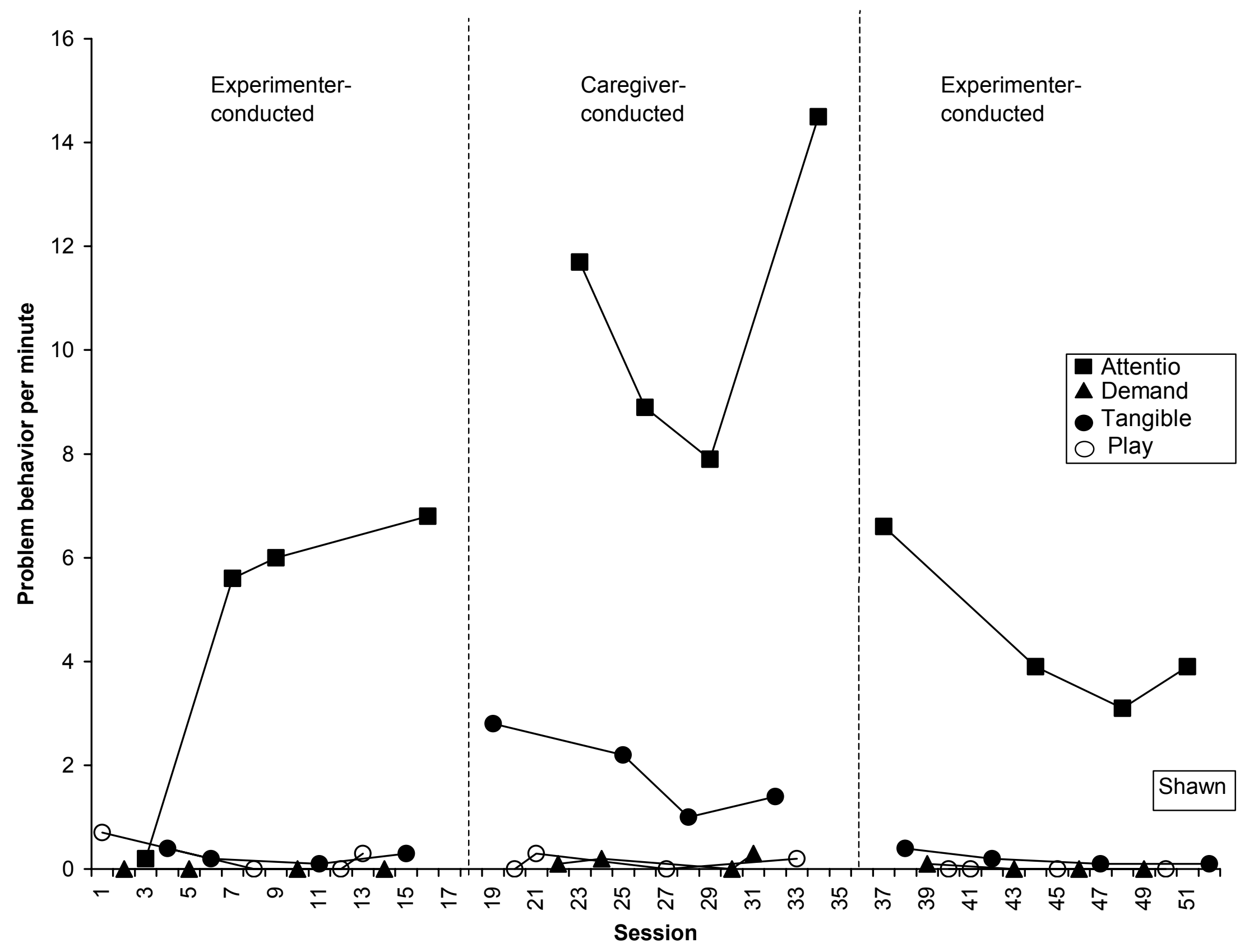




\section{Figure Captions}

Figure 1. Rate of problem behavior per minute during caregiver-conducted and experimenterconducted phases of the analog functional analysis for Brandon.

Figure2. Rate of problem behavior per minute during caregiver-conducted and experimenterconducted phases of the analog functional analysis for Donna.

Figure 3. Rate of problem behavior per minute during caregiver-conducted and experimenterconducted phases of the analog functional analysis for Natalie.

Figure 4. Rate of problem behavior per minute during caregiver-conducted and experimenterconducted phases of the analog functional analysis for Shawn. 